\title{
PARA UM OUTRO ARQUÉTIPO DE ESCOLA: A NECESSIDADE DE MUDAR AS POLÍTICAS E AS PRÁTICAS CURRICULARES
}

\author{
José Carlos Morgado*
}

RESUMO: As mudanças que têm procurado instituir-se no domínio educativo requerem, pelo menos ao nível dos normativos que as determinam, uma maior participação das escolas e dos agentes comunitários nas decisões educativas e na construção de um projeto pedagógico comum capaz de conciliar os propósitos de âmbito nacional com os anseios e as necessidades de cada comunidade. Procura-se que a escola se assuma como uma instituição de referência, capaz de encontrar respostas favoráveis e garantir a diversidade formativa, o que implica a assunção de maiores margens de autonomia, uma (re)atualização constante e a inovação das práticas curriculares que se desenvolvem no seu interior. No entanto, muitas das mudanças que hoje se "exigem" às escolas dependem tanto de um conjunto de decisões oriundas do seu exterior, algumas delas sucessivamente adiadas, como daquilo que se passa no interior da instituição escolar. É sobre algumas dessas questões que refletimos ao longo do texto, indicando alguns caminhos que poderão, eventualmente, contribuir para essas mudanças.

Palavras-chave: Escola; Currículo; Políticas Curriculares; Práticas Curriculares.

\section{FOR ANOTHER ARCHETYPE OF SCHOOL:}

\section{THE NEED TO CHANGE CURRICULUM POLICIES AND PRACTICES}

ABSTRACT: The changes that have been taking place in the educational domain require greater participation of schools and communities in educational decisions and in the construction of a common pedagogical project that will articulate national goals with the needs and expectations of each community. This is what happens at the level of normative discourse. The school is expected to become a model institution that will comply with normative demands and, at the same time, ensure curriculum diversity. This implies greater autonomy for schools, continuous updating, and innovation on curriculum practices that take place within those schools. However, many changes that are 'required' of schools nowadays are determined both by decisions that come from the outside - some of which constantly postponed - and by what happens inside schools. This text presents some reflections on these issues, pointing out some ways that might contribute to the expected changes.

Keywords: School; Curriculum;, Curriculum Policies; Curriculum Practices. * Professor do Departamento de Estudos Currículares e Tecnologia Educativa do Instituto de Educação da Universidade do
Minho. E-mail: jmorgado@ie.uminho.pt 


\section{Introdução}

O debate sobre a escola ou, mais concretamente, sobre a "crise da escola" continua na ordem do dia, o que demonstra, por um lado, a importância que a educação continua a merecer no imaginário social e, por outro, a clara dificuldade de compreender as mudanças que sofreu nos últimos anos e as que precisa concretizar para conseguir dar resposta aos desafios com que se confronta.

Na opinião de Rui Canário (2005, p. 183), a dificuldade em compreender as mutações que a escola foi sofrendo resulta tanto do "processo de naturalização" a que ela foi estando sujeita, quanto do fato de "o monopólio educativo" conquistado pela escola pública contribuir para a fechar sobre si mesma e a privar de "referenciais externos" que ajudariam à sua crítica e transformação. Acrescenta, ainda, que tal dificuldade não se circunscreve apenas ao domínio educativo, inserindo-se num "fenómeno mais geral de défice de capacidade crítica" que perpassa a própria sociedade contemporânea.

Não nos surpreende que assim seja, uma vez que as relações simbióticas que existem, e sempre existiram, entre a escola e a sociedade são "interacções dialécticas onde, quer a escola, quer a sociedade são simultaneamente determinantes e determinadas" (FERNANDES, 1991, p. 60). Se a escola é um episódio do próprio tecido social, a verdade é que, em simultâneo, se torna imprescindível para a construção, modelação e manutenção dessa macroestrutura. É nesse sentido que Mariano Enguita (2007) assevera que as escolas tendem a ser conservadoras/reprodutoras quando integram sociedades mais estáveis, mais estáticas, assumindo-se, porém, como entidades transformadoras quando inseridas em sociedades mais dinâmicas, que procuram decidir o rumo a seguir.

No entanto, não podemos deixar de ter em atenção que, quando "as sociedades dinâmicas seguem um rumo errático ou imprevisível”, as escolas podem ver-se rapidamente "imersas num desvairo completo" que desemboca, por norma, numa crise que torna visível quer a sua "insustentabilidade dinâmica", quer a sua incapacidade para desenvolverem novas oportunidades (ENGUITA, 2007). Curiosamente, é numa situação idêntica à que acabamos de descrever que se encontram hoje muitas das nossas escolas, nomeadamente em Portugal, que continuam a configurar-se mais como locais de execução de medidas oriundas do seu exterior do que 
como espaços de decisão política e curricular, situação a que acresce, ainda, certa "erosão" do estatuto profissional dos docentes.

Importa, por isso, refletir sobre as seguintes questões:

- Será que os desafios de mudança colocados às escolas, em resultado das intensas transformações científicas e tecnológicas e das novas formas de organização social e econômica que caracterizam o mundo contemporâneo, em vez de gerarem mudanças educacionais positivas estão a corroer o otimismo, a esperança e as capacidades profissionais dos professores?

- Que podem as escolas, em particular os professores, fazer para contrariar essa tendência e para debelar certa incapacidade coletiva de reação que se foi instalando no seio da classe docente?

- Que condições - políticas, pedagógicas e materiais - são necessárias para mudar as instituições escolares e recuperar o reconhecimento e o protagonismo perdidos?

- Que medidas políticas e educativas devem ser adotadas para, no imediato, se tentar inverter toda essa situação?

- Será que podemos/devemos continuar a falar de autonomia curricular?

- Por que se torna imprescindível mudar as práticas curriculares e desenvolver culturas de colaboração nas escolas?

É, pois, a partir dessas questões que pretendemos refletir ao longo deste texto, embora facilmente se compreenda que, no espaço de que dispomos para esta comunicação, seja impossível abordá-las na totalidade e com a profundidade que seria desejável. Mesmo correndo o risco de, como alerta Karl Popper (1999), esta reflexão se inserir mais numa lógica de "reconhecimento" e confirmação do que tem sido produzido neste domínio, do que numa lógica de "produção" de novos conhecimentos, decidimos abordar as questões formuladas referindo alguns aspectos que, em nosso entender, têm concorrido para configurar o cenário educativo atual e para caracterizar a profissão docente, bem como para fundamentar a necessidade, cada vez mais premente, de mudar as práticas curriculares que se desenvolvem nas escolas e nas salas de aula.

$\mathrm{Na}$ estrutura do texto, tivemos ainda em conta dois aspectos que nos parecem relevantes. Em primeiro lugar, o fato de ser difícil entender a ação educativa como um processo social sem lhe serem atribuídos objetivos específicos, objetivos esses que traduzem as opções estratégicas e as 
prioridades das políticas educativas que, em determinado momento, se afirmam. Qualquer análise do fenômeno educativo assume, por isso, cariz social e político e, no nosso caso, justifica a referência que fazemos às políticas educativas e curriculares ao longo do texto.

Em segundo lugar, e não menos importante que o primeiro, o contexto histórico em que todo esse processo se desenvolveu. O estudo da realidade educativa deve, sempre que possível, partir de um deslinde cronológico que nos ajude a compreender as transformações processuais e evolutivas no campo educativo. Como destaca Alejandro Ferrer (2002a, p. 15), o conhecimento da evolução que experimentou a educação ao longo do tempo "constitui um elemento de indubitável valor para a formação dos profissionais que desenvolvem a sua tarefa nos sistemas educativos actuais"; além de propiciar recursos intelectuais para analisar e interpretar cada contexto de trabalho numa perspectiva histórica, tal conhecimento permite "desenvolver uma consciência histórica, de carácter crítico, que deve precavê-los em relação às abundantes concepções deterministas e explicações intemporais dos factos educativos em que participam”. Assim se percebe como é difícil problematizar o futuro sem conhecermos o passado e compreendermos o presente.

Com base nos pressupostos enunciados, organizamos o presente trabalho em torno de três eixos de análise: (1) o primeiro, que intitulamos "Evolução histórica do 'figurino' educativo", onde fazemos uma breve análise dos diferentes paradigmas escolares ao longo do século XX, do papel desempenhado pelo Estado na configuração desses "formatos" educacionais, das políticas educativas e curriculares vigentes e dos modelos de ensino e de professor que foram prevalecendo; (2) o segundo, que designamos por "Situação atual - que perspectivas?", ao longo do qual fazemos uma reflexão sobre o conjunto de tensões que, externa e internamente, podem condicionar o trabalho dos professores e a mudança do edifício educativo; (3) o terceiro, um segmento que denominamos "Para um outro arquétipo de escola" e no qual referimos algumas mudanças que, em nosso entender, urge imprimir para a que a escola e os professores se possam ver ressarcidos do protagonismo que foram perdendo e recuperar o lugar de referência que, por direito próprio, lhes cabe no desenvolvimento da sociedade do século XXI. Por fim, elaboramos uma breve conclusão em que enaltecermos a importância que a educação continua a granjear na matriz civilizacional dos nossos dias, chamamos a aten- 
ção para as responsabilidades acrescidas com que a sociedade se depara em termos educativos e relevamos o papel que a escola ocupa no processo de desenvolvimento, integração e promoção de cada indivíduo, permitindo-nos assim compreender por que nela continuam a repousar muitas das esperanças e expectativas de melhoria da sociedade futura.

\section{Evolução histórica do "figurino" educativo}

Vários autores ${ }^{1}$ coincidem ao assinalar a existência de três "momentos" distintos na (re)configuração da escola ao longo do século XX.

\subsection{A escola como "episódio" de estabilidade}

O primeiro momento, que havia de prolongar-se até meados do século, foi conotado como um período de afirmação da escola e fica marcado pela importância que as instituições escolares granjearam quer em termos didáticos e pedagógicos, quer em termos políticos, econômicos e sociais.

Estávamos em presença do que Rui Canário (2005, p. 67) designa por período da "escola das certezas", para se referir a uma instituição coerente, com forte legitimidade social, que cumpria cabalmente os mandatos que lhe estavam consignados. A nível político, a escola assume-se como uma entidade de referência na promoção da cultura e identidade nacionais, tendo desempenhado importante papel na [emergência e] consolidação do Estado-nação. Do ponto de vista social, a escola contribui para a criação de uma "nova ordem", fundada num "novo tipo de laço social", construído em torno da emergência da relação salarial e do declínio do paradigma rural mais tradicional, e num estatuto social que deixa de ser transmitido por via familiar e passa a ser adquirido pela ação individual, "no quadro de estruturas sociais marcadas por uma crescente mobilidade" (CANÁRIO, 2005, p. 66). Em termos econômicos, a escola configura-se como um elemento charneira na produção de mão de obra disciplinada, capaz de se adequar às diferentes modalidades resultantes da "crescente racionalidade da organização do trabalho, baseada na hierarquia, na segmentação das tarefas e na dissociação entre o trabalhador e o produto do seu trabalho" (CANÁRIO, 2005, p. 67). 
No que diz respeito à organização pedagógica da escola, esta elabora-se a partir de uma estrutura nuclear - a classe -, entendida como um grupo de alunos que recebe, em conjunto e de forma simultânea, o mesmo ensino. Trata-se, como sustenta João Barroso (2001, p. 69), de um "modo de organização pedagógica" que se consubstancia no princípio de "ensinar a muitos como se fossem um sô". Uma "forma escolar" onde prevalece o princípio da homogeneidade, determina a "organização do espaço, do tempo, dos saberes" e representa uma "marca distintiva da escola" (CANÁRIO, 2005, p. 76). Essa solução organizacional, que rapidamente se naturalizou e que, a despeito das constantes críticas que foi sofrendo, por se configurar como uma das "invariantes educativas" que mais dificulta a mudança da escola, se perpetuou até aos dias de hoje, revelou-se extremamente eficaz para concretizar os desígnios que norteavam a educação da altura - a divisão do trabalho dos alunos, a especialização das funções docentes e a consolidação de uma escola de elite, fundada num paradigma educativo baseado numa lógica cumulativa e repetitiva de informações, em que a compartimentação de saberes e a memorização se assumem como principais elementos estruturantes. A esse respeito, João Barroso (2001) assevera que

a classe, que era inicialmente uma simples divisão de alunos, transforma-se progressivamente num "padrão" organizativo para departamentalizar o serviço dos professores e o próprio espaço escolar. Simultaneamente, adquire o valor de "medida" na progressão dos alunos (passar de "classe") e na divisão temporal do percurso escolar (o termo "classe" vai-se tornando sinónimo de “ano" de escolaridade) (BARROSO, 2001, p. 69).

Relativamente ao papel do Estado, estávamos em presença do que vários autores designam como "Estado Educador", uma vez que lhe competia a provisão da educação e a criação de condições para a subsistência, o funcionamento e a regulação do sistema de ensino. Ao Estado arrogava-se o direito de, ao bom estilo centralista, interferir no que considerava conhecimento útil e nas determinações sobre os curricula, os planos de estudo, os parâmetros de avaliação, entre outros. Daí o pendor centralista, uniformizador e impessoal que revestiu o currículo escolar, idealizado como instrumento propício para a consecução de uma efetiva racionalidade administrativa, sendo, por isso, identificado metaforicamente durante muito tempo como "currículo uniforme pronto-a-vestir de tamanho único” (FORMOSINHO, 1987). 
Por seu turno, Mariano Enguita (2005, p. 26)², numa reflexão que faz a partir da relação entre educação e mudança social, em que procura, por meio de mudanças substanciais nas formas de vida, de trabalho e convivência, averiguar se a escola terá contribuído mais para preservar ou transformar a sociedade, considera esta época como um período de "mudanças suprageracionais", isto é, um período em que as mudanças existem mas não são perceptíveis de uma geração para a outra, tanto pela sua lentidão quanto por afetarem apenas grupos minoritários. Assim se compreende que, para a maioria dos cidadãos, a família e a comunidade imediata tivessem papel educativo relevante, reservando-se a instituição educativa apenas para determinada camada populacional mais elitista. A educação funcionava numa lógica claramente reprodutora da estrutura social vigente.

Esse modelo viria a ser fortemente abalado com o deflagrar da Segunda Guerra Mundial, que representou um marco importante no desenvolvimento dos sistemas educativos contemporâneos. O impacto dos acontecimentos produzidos pela guerra foi muito amplo e fez sentirse em diversos âmbitos, não constituindo exceção o campo educativo. A assinalável perda de vidas humanas, a ruína das economias e a grande destruição de bens de todo tipo, sobretudo nos países diretamente implicados no confronto, produziram fortes comoções e estiveram na base de muitas das dificuldades sentidas para tentar levar a cabo a necessária reconstrução política, econômica e social em cada país.

Entrava-se num novo período da história da humanidade, "um período de consenso, de fé na autoridade e na legitimidade", tornando-se perceptível que o final da guerra tinha "gerado uma corrente de promessas e de esperança numa nova era caracterizada por mudanças progressivas na relação entre o Estado e a sociedade" (HELD, 2001, p. 265).

\subsection{A escola como "motor" de desenvolvimento}

O princípio de que a educação se revelava como um dos principais argumentos para a reconstrução e o desenvolvimento de cada país, associado à ideia de que o Estado devia assumir a tarefa de (re)organizar um sistema de ensino que proporcionasse escolarização de base a toda a população, aspectos de resto vinculados à origem do Estado liberal e à génese dos sistemas educativos ocidentais em finais do século XVIII e princípios do século XIX, veem-se agora reforçados e são reconhecidos como elementos preponderantes a ter em consideração. 
A esse propósito, assinala George Papagiannis (1992, p. 4646) que tanto a reforma dos sistemas de ensino quanto a expansão da educação se tornaram preponderantes, ao serem reconhecidas "como elementos chave no complexo processo de potencializar o crescimento económico, de conseguir a modernização política e social e de formar cidadãos de mente crítica, independentes e participativos". Não surpreende, pois, que desde os primórdios da década de 1950 se tenham feito grandes investimentos na (re)construção e no desenvolvimento dos sistemas educativos de muitos países, particularmente na Europa, assistindo-se a uma evolução caracterizada, fundamentalmente, "pela sua expansão quantitativa, pela sua abertura a novos públicos e pela sua contribuição para o desenvolvimento de novos estilos de organização política e social" (FERRER, 2002b, p. 260).

Inicia-se, assim, um segundo momento na história da educação, que começa no pós-guerra e se vai estender até meados dos anos setenta, época em que dealba a forte recessão econômica que viria a assolar o Mundo. A escola configura-se como uma mais-valia em termos de desenvolvimento econômico e assiste-se à tentativa de democratizar o acesso à escola, o que desembocaria no fenômeno de "explosão escolar" a que temos assistido desde essa altura e à edificação da comummente designada "escola de massas". Não surpreende, pois, que a maioria dos autores considerem esse período como a passagem de uma escola elitista para uma escola de massas e, por isso mesmo, um dos mais importantes na democratização da educação.

Afirmava-se, assim, um período de mudanças que Mariano Enguita (2005, p. 27) apelida de "mudança intergeracional", no qual as mudanças são claramente perceptíveis de uma geração para outra, por grupos significativos da população. Adianta o autor (ENGUITA, 2005, p. 32) que, nesse período, a escola e a docência se configuram como elementos cruciais do progresso em relação à tradição, do futuro em relação ao passado e da razão em relação à superstição. É uma época gloriosa, em que os professores sentem que lhes é confiada uma missão, reconhecida pela sociedade, o que contribui para verem, ainda que não por muito tempo, elevar o seu estatuto profissional.

Na opinião de Rui Canário (2005, p. 78-79), o "crescimento exponencial da oferta educativa escolar", em resultado do aumento da oferta e do acréscimo de procura, faria entrar a escola numa fase que designa 
como o período da "escola das promessas", expressão que traduz a associação do fenômeno educativo a três promessas fundamentais: "uma promessa de desenvolvimento, uma promessa de mobilidade social e uma promessa de igualdade". Acrescenta o autor (CANÁRIO, 2005) que essa onda de euforia e otimismo em relação à escola é concomitante com a construção de um Estado-providência que, ao reconhecer o crescimento do sistema educativo como "factor económico de primeira importância" e ao assumir a sua gestão como uma "grande empresa", adquire as características de um "Estado desenvolvimentista".

Convém lembrar duas teorias que, segundo George Papagiannis (1992, p. 4647), contribuíram para potenciar a "ideia de que a expansão e o desenvolvimento educativos podiam superar a pobreza e o subdesenvolvimento": a teoria do capital humano ${ }^{3}$ - que defende uma correspondência direta entre o desenvolvimento educativo e o crescimento econômico - e a teoria funcional e modernista ${ }^{4}$ - segundo a qual "a invenção, a tecnologia e a inovação" são consideradas como forças capazes de "aumentar a capacidade económica e social dos indivíduos".

Simultaneamente, ganha relevância e aceitação a corrente de planificação macroeconômica proposta por John Keynes (1974), que propõe maior intervenção do Estado por forma a garantir, por meio de políticas fiscais progressivas, os direitos e os serviços sociais a toda a comunidade, considerados agora como imperativos fundamentais de qualquer sociedade democrática. Do ponto de vista político, a progressiva tomada de consciência do direito de cada indivíduo à provisão pública de uma série de serviços sociais, destinados a cobrir necessidades humanas básicas (educação, assistência sanitária, pensões, habitação), justificavam, por si só, a intervenção do Estado no sentido de garantir tais prestações, contribuindo assim para a maior justiça social.

Assim se compreende que, de forma similar ao que aconteceu a nível econômico e social, onde foi necessário um poder político forte, capaz de fazer vingar os direitos coletivos em detrimento dos interesses individuais e de controlar os mecanismos e as forças de mercado, também no campo educativo se percebeu a importância de o Estado assumir idêntico protagonismo. A educação como direito social de qualquer cidadão passa a ser vista como um ideal possível de atingir, cabendo ao Estado a responsabilidade de proporcionar os meios e os recursos necessários para sua concretização. 
Como consequência, a maioria dos países ocidentais viveu um período de acentuado centralismo educativo. Os respectivos governos, baseando-se em imperativos de igualdade e democratização social e escolar, acabam por controlar os destinos educacionais e ter uma intervenção direta nos respectivos sistemas de ensino. Predominam os sistemas educativos centralizados, que embora teoricamente se digam ao serviço da democratização do ensino acabam, na prática, por servir mais à função educadora do Estado do que à participação democrática dos docentes e dos estudantes nas decisões educativas.

As políticas educativas centralizadas, que estariam na base de um conjunto de reformas educativas impostas pelo poder central, acabaram por gerar autoritarismo, conformismo e uma tendência comum para uniformizar o ensino e a formação. A escola vai-se tornando cada vez mais refém das diretrizes emanadas pela administração educativa e converte-se num espaço propício para a aplicação de políticas educativas definidas a nível central. Os professores limitam-se a cumprir normas e a executar os programas prescritos para cada disciplina e/ou ano de escolaridade - prevalece o interesse pelos resultados (produtos) em detrimento da importância dos processos de ensino-aprendizagem e da seleção dos conteúdos.

Em suma, as políticas educativas centralizadas acabaram por fomentar a configuração de sistemas educativos uniformes, rígidos e burocráticos, com esquemas de funcionamento em que os critérios administrativo-burocráticos prevalecem sobre os de natureza pedagógica, protagonizando modelos educativos mais direcionados para a transmissão de conhecimentos e a obtenção de resultados visíveis a curto prazo do que para as dimensões humanas e sociais que devem servir de esteio aos processos de ensino-aprendizagem.

No dealbar da década de 1970, toda a estratégia expansionista da reforma educativa e as ideias que a consubstanciaram - educação como via para mudar o mundo, investimento na educação como de fomentar o desenvolvimento econômico e a igualdade social, investimento social como estratégia para legitimar os regimes democráticos - começaram a evidenciar sinais de debilidade.

A esse prenúncio da crise escolar não foi alheia a forte recessão econômica resultante da crise do petróleo de 1973, cujas consequências fizeram diminuir os gastos que os Estados vinham fazendo em vários setores sociais, nomeadamente no campo educativo ${ }^{5}$, enfraquecendo assim o oti- 
mismo pedagógico que vinha imperando até essa altura. No que diz respeito à escola, afirma Canário (2005, p. 80), a expansão da "escolarização de massas" não se traduziu nem na "generalização do 'bem-estar' à escala mundial, nem na ultrapassagem do fosso que separava os países 'desenvolvidos' dos que se encontravam 'em vias de desenvolvimento' ou em situação de 'subdesenvolvimento"'.

Não podemos, a esse respeito, deixar de referir uma importante crítica às estratégias reformistas das décadas anteriores que surgiu pela voz de Philipe Coombs (1971, p. 10), numa Conferência Internacional sobre a Crise Mundial da Educação, realizada no estado de Virgínia (EUA.), em 1967. Não deixando de reconhecer que "os sistemas educativos se tinham desenvolvido e modificado mais rapidamente do que nunca", considera que não o teriam feito com a devida celeridade, respondendo com demasiada lentidão "ao rápido compasso dos acontecimentos a que se encontravam circunscritos". Demonstrando sempre uma profunda preocupação com a educação e enorme otimismo relativamente ao futuro, Coombs (1971) não deixou de assinalar que o aumento dos custos da educação, a crescente procura de títulos escolares, o excessivo número de abandonos, a explosão demográfica e a recessão econômica teriam, em conjunto, conduzido ao que denominou por "crise mundial da educação". Com efeito, as políticas educativas e curriculares vigentes nesse período concorreram mais para privilegiar uma dimensão instrumental e utilitarista da educação e do currículo do que para uma afirmação de valores, do desenvolvimento humano e da construção da cidadania. Permitiram que continuasse a perpetuar-se um paradigma educativo mais consonante com a submissão, a passividade e a uniformidade do que o pensamento autônomo, a liberdade, a capacidade de resolução de problemas e a reflexão crítica. Uma situação que acabaria por conduzir a um progressivo alheamento da escola em relação aos contextos em que se encontra inserida e por produzir elevadas taxas de insucesso e de abandono escolar.

Em termos curriculares, continuaram a prevalecer a lógica do currículo nacional, o peso da prescrição curricular e a tendência de a administração continuar a controlar o currículo tanto ao nível do seu conteúdo quanto da sua forma (MORGADO, 2003). Embora se questionem quer "as práticas de isolamento da escola face à comunidade", quer a "qualidade de um currículo nacional que é construído à prova dos profes- 
sores" (LEITE, 2005, p. 18), a verdade é que às escolas e aos atores educativos é apenas consignado o papel de meros executores de decisões que outros prescreveram, remetendo os professores para o estatuto do funcionalismo público e para a posição de meros técnicos curriculares.

A esse cenário não são alheias nem as mudanças que, entretanto, se desencadearam a nível econômico, político e social, nem a crise política que assolou o Estado-providência, visível pelas suas limitações na gestão da vida coletiva e pela crescente falta de credibilidade das instituições políticas, o que, por si só, justificou a procura de novos modelos de solidariedade e de governo pela sociedade civil. Inicia-se, assim, um novo período, que intitulamos de "escola como artefacto de criatividade e inovação".

\subsection{A escola como espaço de "criatividade" e de "inovação"}

O terceiro momento, que abrange o último quarto do século $\mathrm{XX}$, configura-se como um período em que a escola, em resultado da catadupa e da rapidez das mudanças que ocorreram em diversos setores sociais, se vê rapidamente imersa num conjunto de reformas e desafios que a (re)colocam no centro do debate educacional e a confrontam com a necessidade de se reorganizar, sob pena de, se o não fizer, vir a ser atacada por um surto de obsolescência e a ficar relegada para meras funções de custódia ou, como refere Green $(1997)^{6}$, a funcionar como um "parque de estacionamento" de potenciais desempregados, assumindo-se "o prolongamento de estudos (no contexto da escola ou da formação profissional) como uma panaceia para conter artificialmente os problemas do desemprego e do sub-emprego que tendem a assumir uma carácter endémico e a ser minorados através das políticas de formação".

Na configuração desse cenário, que Rui Canário (2005, p. 81-84) intitula como a era da "escola das incertezas", tiveram peso significativo a erosão e o défice de legitimidade do Estado-providência - a que se associam a progressiva emergência de um Estado mínimo (Estado Regulador) -, a globalização - cujas consequências imediatas foram a progressiva liberalização dos mercados, a livre circulação de capitais e o avanço das forças do mercado -, as transformações no mundo do trabalho - com o aumento dos níveis de desemprego estrutural e a precarização dos vínculos laborais -, a progressiva incapacidade coletiva de reivindicação por parte das tradicionais estruturas sociais - caso das associações profissio- 
nais e dos sindicatos que se veem constantemente relegados para segundo plano no campo das decisões - e, ainda, a inflação e progressiva "desvalorização dos diplomas escolares" - em resultado da acentuada discrepância entre "o aumento da produção de diplomas pela escola e a rarefacção de empregos correspondentes".

A escola submerge, assim, no que Mariano Enguita (2005, p. 27) identifica como período de "mudanças intrageracionais", para se referir a uma etapa em que as mudanças são perceptíveis, de forma generalizada, dentro de uma mesma geração e nos aspectos estruturantes da experiência humana: economia, política, cultura, família, entre outros. Nesse sentido, afiança que as transformações no mercado de trabalho, na organização empresarial, nas formas de comunicação e de acesso à informação, na estrutura da vida urbana e nas relações sociais obrigaram a uma readaptação das populações "a novas condições de vida, de trabalho e de sociabilidade" (ENGUITA, 2005, p. 33), com reflexos evidentes ao nível da instituição escolar, que se vê confrontada com a necessidade de concretizar novas formas de aprendizagem, ancoradas em novas competências e ao longo de toda a vida "útil" dos indivíduos.

Em face da crise com que se deparou o Estado nacional desde o início da década de 1980, e para fazer face às mudanças e às exigências que se colocam às escolas, os governos de diversos países encetam uma série de reformas das respectivas administrações públicas, reformas essas que se foram concretizando "desde uma perspectiva mais centrada na transferência de poderes entre os vários níveis da administração (descentralização)", com a inerente "alteração de processos de decisão e gestão (nova gestão pública), até perspectivas mais radicais de liberalização e privatização do sector público", isto é, a adoção de uma lógica de mercado (BARROSO, 1998, p. 36). Tratando-se de posições distintas em relação ao protagonismo do Estado e à dimensão do serviço público, essas perspectivas acabariam por coexistir e conviver no panorama social, interferindo e condicionando as reformas em vários setores, particularmente no âmbito das políticas sociais e educativas.

No terreno educacional, as intenções de reformar os sistemas de gestão burocráticos e de promover a participação dos vários atores sociais nos destinos educativos passam a ser uma referência obrigatória na generalidade dos discursos políticos e educacionais. Prevalece a ideia de que a gestão participada dos sistemas educativos e das escolas pode ajudar a 
resolver a crise que atravessa a educação. O tema da "autonomia da escola" passa a ser referência obrigatória da retórica governativa e da produção normativa e as escolas passam a ser consideradas como lugares estratégicos de decisão política, devendo, por isso, assumir-se como estruturas capazes de produzir respostas eficazes para as necessidades das comunidades em que se inserem.

Só que, nem sempre aquilo que se propala a nível dos discursos se concretiza ao nível das práticas. Exemplo disso é o que se passa da "autonomia da escola", expressão com um campo semântico de largo espectro e que, na opinião de João Barroso (2006, p. 25-35), pode originar "modos de fazer" distintos, permitindo-lhe, no caso de Portugal, identificar três significados políticos associados às medidas de reforço da autonomia das escolas:

- autonomia como retórica discursiva - o discurso da autonomia da escola, que visava a transladar responsabilidades dos governos centrais para os contextos locais e mobilizar os atores sociais para a mudança, acabou por se desenvolver num "contexto conservador, domina por administração burocrática e centralizada", o que fez com que a autonomia, mais do que uma vontade emergente da escola ou de uma forma de resolução de problemas por parte da administração central, se restringisse a ser utilizado para "mobilizar as 'escolas' para aceitar as mudanças a introduzir pelo centro do poder político" e, mais preocupante, para legitimar novas modalidades de controle; assim se compreende que "as políticas de descentralização" aparecessem associadas ao reforço da avaliação e à prestação de contas, tentando a administração "não perder em 'autoridade" aquilo que ganhou em "legitimidade";

- autonomia como instrumento de governação - as medidas de reforço da autonomia foram utilizadas como um "instrumentos de acção pública", isto é, como artefatos que permitem predeterminar e "estabilizar formas de acção colectiva", tornando "mais previsível" e, ao mesmo tempo, "mais visível o comportamento dos actores"; é nesta lógica que se inscrevem os "contratos de autonomia" que, ao mesmo tempo que combinam "uma estratégia de negociação, a mobilização dos actores e a promoção da sua autonomia", acabam por propiciar "um sentido de controlo e garantia de resultados", numa lógica de "obediência a princípios ou normas gerais";

- autonomia como modo de regulação - o reforço da autonomia das escolas integra-se no que vem sendo comumente designado por "novos 
modos de regulação das políticas e da acção educativas" e que simboliza a passagem de um "modelo de regulação burocrático-profissional", baseado na combinação de uma regulação estatal, burocrática e administrativa com uma regulação profissional, corporativa e pedagógica, para um "modelo de regulação pós-burocrático", organizado a partir dos conceitos de "Estado-avaliador" e de "quase-mercado" educativo e que se caracteriza pela concessão de um maior grau de autonomia das escolas, pela promoção da "livre-escolha" da escola, pela diversificação da oferta escolar, por um equilíbrio entre centralização e descentralização, pela introdução de mecanismos de avaliação externa e pela prestação de contas.

Pesem embora os diferentes sentidos de que pode se revestir a administração educativa, constatamos que o cerne da governação educacional permanece ainda, em boa medida, sob a alçada do Estado, embora não sejam de descurar nem os efeitos que a globalização provocou ao nível das políticas educativas nacionais, como consequência da reorganização das prioridades dos Estados no sentido de maior competitividade e de atrair investimentos internacionais (DALE, 2001), nem a influência das correntes neoliberais que, baseadas na restrição pelo Estado das liberdades individuais, na "garantia" de conseguir resolver os problemas que aquele não foi capaz, na diminuição dos gastos públicos, na necessária competitividade do mercado e em promessas de maior equidade e justiça social, pretendem apenas "criar mercados (ou quase-mercados) educativos" e transformar a ideia de "serviço público" em "serviços para clientes", em que o "bem comum para todos" é substituído por "bens diversos, desigualmente acessíveis" (BARROSO, 2006, p. 37). De um modo geral, podemos dizer que as influências transnacionais e/ou supranacionais (caso da União Europeia no contexto educativo português) na definição das políticas educativas e curriculares, bem como as argumentações neoliberais que as aconchegaram, se materializaram num conjunto de medidas e de estratégias que, sob a égide da eficácia da escola, da flexibilização da oferta educativa, da racionalização dos dinheiros públicos, da rentabilização de recursos, da melhoria da qualidade do ensino, pretenderam, sobretudo, cativar a adesão do senso comum e aplicar à instituição escolar esse maniqueísmo intelectual que tende a deteriorar e desvalorizar a imagem do público, a exaltar as bondades do mercado e a servir determinados interesses mais particulares.

Em termos curriculares o panorama foi idêntico. $O$ fato de a descentralização e a autonomia serem frequentemente invocadas como 
formas de transferência/apropriação dos poderes de decisão curricular a concretizar pelos agentes no terreno, a verdade é que, na prática, nunca corresponderam a uma entrega aos professores e às escolas do processo de (re)construção do currículo, nem englobaram uma alteração da matriz curricular vigente, servindo tais discursos mais para fundamentar linhas de orientação política baseadas na eficácia, qualidade, excelência dos resultados e prestação de contas (MORGADO; FERREIRA, 2006). O binómio curricular (ROLDÃO, 1999) ${ }^{7}$, em torno do qual deveriam territorializar-se as políticas e as práticas de decisão curricular, acabou por pender mais para o lado da administração central, com o currículo nacional, de teor prescritivo e uniformizante, a prevalecer sobre a construção de projetos curriculares pelas escolas, aqui entendidos como meios de cada instituição escolar adequar e operacionalizar um core curriculum $^{8}$ em função do contexto em que está inserida e das necessidades e características dos alunos que a frequentam.

Chegados ao fim do século XX, o que se constata é que a escola, idealizada inicialmente como um espaço nacional, foi tecendo ao nível das suas práticas um modelo de gestão científica, ancorado nos princípios da eficiência global (taylorismo) e nos pressupostos de uma teoria curricular de natureza instrucional (racionalidade tyleriana) (PACHECO, 2003). Tal modelo, que tem por base a disciplinarização do conhecimento e a abordagem sistêmica foi-se perpetuando e mantendo até aos dias de hoje. A escola continua a funcionar num regime de classes (BARROSO, 2001) e a manter uma estrutura curricular organizada por disciplinas, isto é, um conhecimento compartimentado, fragmentado e reduzido a fronteiras muito fechadas que em nada favorecem o diálogo interdisciplinar (PACHECO, 2007), nem a assunção de uma postura deliberativa por parte dos professores.

Em suma, a escola que, sob a égide da modernização e no âmbito do movimento de descentralização que envolveu o último quartel do século XX, se deveria libertar da tutela do Estado e assumir como um local privilegiado de participação e decisão democrática dos agentes que nela laboram, acabou por ficar refém de uma estratégia que poucas alterações propiciou e que acabaria por dificultar sua reconfiguração como espaço de criatividade e inovação, indispensável à mudança e à melhoria do serviço educativo que proporciona. 


\section{Situação atual - que perspectivas?}

Neste segmento, que intitulamos como "situação atual - que perspectivas?", refletimos sobre as mudanças que os sistemas educativos e as escolas vivem, sobretudo no período de transição para o século XXI, nomeadamente no contexto educativo português, terminando com uma pequena reflexão mais prospectiva sobre o cenário educativo e curricular nos tempos futuros mais próximos.

Nos anos mais recentes, que marcam o fim do ciclo de políticas educativas desenvolvidas a partir dos anos setenta, temos assistido, em diversos países, à emergência de um movimento de reforma baseado em standards (standards-based reform) ${ }^{9}$ que, na opinião de Antonio Bolívar (2007, p. 24) tem assumido "O carácter de uma nova 'ortodoxia' da mudança educativa”. Trata-se de uma situação preocupante, se tivermos em conta que a definição de standards, ao determinar os conteúdos que os professores devem trabalhar nas aulas e o que os alunos devem aprender, escrutinando a posteriori por via da avaliação externa (avaliação do desempenho docente e exames nacionais) a consecução, ou não, das finalidades preestabelecidas, se pode configurar [e tem configurado] como uma forma de (re)centralizar os poderes de decisão educativa e curricular e de pressionar politicamente as escolas e os agentes que nela trabalham.

Não deixando de reconhecer, com Elmore $(2000: 4)^{10}$, que a reforma baseada em standards representa uma "mudança fundamental na relação entre a política e a prática docente", podendo até carrear alguns efeitos positivos ${ }^{11}$, a verdade é que tal relação tem contribuído sobretudo para que os contextos de ensino se configurem como "produtores de identidades técnicas", uma vez que os professores têm sido mais avaliados e responsabilizados pelo lado dos resultados dos alunos do que pelo seu lado mais pessoal ou pela gestão dos processos de aprendizagem (PACHECO, 2007).

Também não deixa de ser preocupante que, em muitos países, incluindo Portugal, as políticas educativas que norteiam as reformas, bem como as pressões que delas emanam para "aumentar os resultados na prestação de contas", se vinculem a uma "estratégia mercantil" de fornecimento de créditos aos clientes para fundamentarem a escolha das escolas, mediante a publicação de rankings escolares (BOLÍVAR, 2007, p. 25). Assim se compreende que a esse movimento não seja alheio o fato de a 
globalização, situada no lado da utilidade econômica, favorecer a emergência de identidades ligadas a contextos de ensino mais marcados pelas questões técnicas (gestão da sala de aula, conhecimento da disciplina, resultados dos testes dos alunos) do que pelas questões de natureza pessoal, profissional, social e emocional, concorrendo assim para a criação de uma escola uniforme e homogênea em termos de aprendizagens, com conteúdos orientados para a qualificação de uma mão de obra flexível às contingências da ordem mundial (PACHECO, 2007).

Mais uma vez, estamos em presença de um tipo de reformas que se implementam sob o pretexto de aproximar os sistemas de decisão dos seus principais beneficiários e de colmatar necessidades sentidas por estes, mas que, na prática, acabam mais por responder a imperativos de natureza econômica e de mercado do que a necessidades de índole educativa e social. Ora, não se trata de deixar de ter em conta a importância da dimensão econômica em todos os quadrantes da vida social, incluindo a educação. Aliás, como afirmam Andy Hargreaves e Dean Fink (2007, p. 21), o desafio consiste em não "menosprezar as práticas existentes no mundo dos negócios, mas, antes, em aprender com as mais bem sucedidas”. Só que, tal aprendizagem não pode deixar de ter em atenção que "a educação pública" não deve ser tratada como "um negócio temporário que procura produzir resultados rápidos e lucros incessantes". Enquanto fator essencial para a construção, o desenvolvimento e o progresso da humanidade, a educação deve ser entendida como um processo que conduzirá à maior plenitude e igualdade entre os homens, devendo, por isso, ser entendida como um dos maiores "empreendimentos de longa duração de todos os tempos” (HARGREAVES; FINK, 2007, p. 21). Não ter em atenção esses princípios é negar a sua própria existência como empreendimento humano.

Além do mais, existem poucas evidências concretas de que a avaliação do desempenho dos atores e a prestação de contas provoquem, por si mesmas, a melhoria dos resultados educativos. Pelo contrário, tais propósitos têm servido mais para, por meio do estabelecimento de rankings, alargar o fosso entre as escolas que obtêm melhores e piores resultados. Além disso, quando essa pressão deixa de existir, as escolas regridem rapidamente, tornando visível a inoperância e a fragilidade de tais medidas.

É nessa ordem de ideias que Andy Hargreaves e Dean Fink (2007, p. 21) consideram que esse movimento de reforma educativa está 
a atingir os limites da sustentabilidade, uma vez que "degenerou numa compulsão obsessiva para com a estandardização" - os mesmos programas para todos, uma única forma de os ensinar, uma solução de tamanho único generalizada - e na "aposta numa competição feroz em ambiente de mercado", estando prestes a entrar em colapso. Não deixando de reconhecer a bondade das ideias que presidiram a implementação desse movimento, Hargreaves e Fink (2007, p. 23) consideram que as reformas orientadas para a estandardização têm tido efeitos devastadores - quer no seio da classe docente (sobrecarga de trabalho, excesso de stress, perda confiança, sensação de incompetência, resistência à mudança, erosão das comunidades profissionais, recurso a estratégias dissimuladas e calculistas para a obtenção de resultados), quer ao nível das próprias escolas (desvalorização das escolas inovadoras, destruição da criatividade na sala de aula, estreitamento do currículo, dificuldade em encontrar gestores), quer, ainda, no seio dos próprios alunos (crise eminente de obtenção de diplomas, alunos incapazes de atingir os padrões estabelecidos, conteúdos excessivos) - que estão a provocar o esgotamento de recursos no campo educativo, motivo que tem levado alguns governos a tentar encontrar formas mais prudentes e mais engenhosas de mudança e melhoria educativa.

Em idêntica linha de pensamento, João Barroso (2006) assevera que, sobretudo a partir de meados da década de 1990, a preponderância e a visibilidade das políticas de índole neoliberal, que afinal acabaram por dificultar a promoção do reforço da autonomia das escolas e a preservação do serviço público de educação, começaram a evidenciar claros sinais de debilidade. A falência de uma série de programas de "ajustamento estrutural" no domínio educativo, a não-resolução dos problemas resultantes do "disfuncionamento da burocracia e do centralismo estatal" e a não-participação dos diferentes atores sociais no governo e no controle das escolas (BARROSO, 2006, p. 35) terão sido alguns dos motivos que estiveram na base da onda de críticas que, a partir de diversos setores, se foram avolumando contra os "excessos de liberalismo" e os seus principais "ideólogos". A essas críticas não é alheia a reconfiguração, em diversas partes do globo, das relações entre economia e política.

É nesse contexto que começam a desenhar-se algumas alternativas às políticas dominantes, emergindo inúmeras vozes a favor da recuperação da legitimidade e da autoridade do Estado e da diluição da dicotomia Estado/mercado. Existem mesmo propostas de modos de regulação 
que "defendem um equilíbrio e uma partilha entre a intervenção do Estado e do mercado" (BARROSO, 2006, p. 41). É nesse sentido que Boyer (2001, p. 49-50) ${ }^{12}$ se refere à necessidade de um modelo emergente no início do século XXI, baseado numa "concepção de desenvolvimento fundada na inovação institucional", afiançando que "o sucesso do desenvolvimento" resulta mais da "complementaridade" entre a lógica do Estado e a lógica do mercado do que da "afirmação de uma delas".

Estamos convictos de que, a seu tempo, essas alternativas se refletirão a nível educacional, permitindo, como advoga Meuret (2004, p. 15), que a autonomia da escola seja uma realidade, conduza à eficácia e sirva de suporte a mudanças pedagógicas a "ser utilizadas ao serviço das aprendizagens dos próprios alunos”.

\section{Para um outro arquétipo de escola}

Tal como havíamos referido no início do texto, não podemos deixar de sinalizar algumas medidas que consideramos necessárias para que a escola e, em particular, os professores recuperem o protagonismo perdido, se assumam como verdadeiros profissionais do ensino e contribuam para as tão almejadas mudanças na educação. No fundo, um conjunto de pressupostos cuja concretização permitirá um novo arquétipo de escola.

Em primeiro lugar, é preciso implementar um projeto político nacional que viabilize a promoção e a defesa da escola pública, "enquanto garante da aquisição e distribuição equitativa de um bem comum público", e assegurar modalidades de intervenção e regulação que confiram ao Estado papel determinante nesse processo e estimulem a sua "dimensão sociocomunitária” (BARROSO, 2006, p. 42-44). Tal projeto permitirá não só garantir a universalidade do acesso à educação e a igualdade de oportunidades, mas também estimular o desenvolvimento pleno de todos os cidadãos, independentemente da sua origem ou classe social.

Em segundo lugar, é necessário definir políticas educativas e curriculares que, para além do reforçarem a autonomia das escolas, por meio da concessão aos professores e demais agentes educativos de oportunidades de participação e decisão curriculares, promovam mudanças educativas sustentadas e sustentáveis - sustentadas porque resultam de uma planifica- 
ção que, sem descurar imperativos de espectro nacional ou internacional, não deixam de ter em conta as características e necessidades de cada escola; sustentáveis no sentido que lhe é conferido por Andy Hargreaves e Dean Fink (2007), isto é, mudanças que perduram no espaço e no tempo, dispõem de condições e apoios, incidem mais na aprendizagem do que no ensino ou na escola e potenciam inovações em cada contexto específico.

Em terceiro lugar, é necessário adotar um novo conceito de currículo, entendido simultaneamente como um amplo projeto social e um processo deliberativo, apoiado em efetiva flexibilização e autonomia curriculares, por oposição ao conceito de currículo que tem prevalecido nos sistemas de ensino, um currículo espartilhado, delimitado por territórios disciplinares bem vincados, em que o primado da sequencialidade determina e impõe o conhecimento a ministrar ao aluno. $\mathrm{Na}$ verdade, tem vindo a perpetuar-se uma concepção curricular que (sobre)valoriza os conhecimentos inscritos em áreas de saber específicas e uma organização curricular que gera uma "visão do conhecimento como sagrado e misterioso (e a consequente visão do aluno como ignorante, como carente de socialização na ordem existente)", funcionando o currículo como instrumento de controle dos sujeitos nele implicados (MOREIRA, 2003, p. 63), em detrimento de outra em que o currículo se assuma como construção coletiva, espaço integrador e diferencial, processo que não ignora a existência de uma realidade que se constrói na diversidade (MORGADO, 1999).

Além disso, tem-se verificado mais recentemente certa tendência para enclausurar a escola pública num modelo de prestação de contas, em que alunos e pais são vistos como "decisores-consumidores", relegando os professores para domínios de decisão subjugados ao permanente controle pelos conteúdos e pela avaliação (PACHECO, 2002, p. 145). Tal tendência tem contribuído para consubstanciar uma concepção mais técnica de currículo, idealizado como um conjunto de objetivos e de conteúdos previamente definidos que a escola deve concretizar. Só será possível inverter esse processo se, como afirma Boaventura Santos (1999, p. 199), o currículo se configurar como instrumento flexível e integrador e se valorizar a existência de currículos informais, o que permitirá que a escola se transforme num espaço privilegiado de "encontro de saberes" - onde, sem deixar de se valorizar o saber científico que aí se produz e transmite, se (re)valorizam também os saberes não-científicos -, isto é, uma escola "a várias vozes". 
Em quarto lugar, é preciso "desalienar o trabalho escolar", o que só é possível se o aluno se sentir como sujeito no processo de ensino-aprendizagem, implicando-o numa perspectiva de produção de saber, e a escola se configurar como um espaço "onde se desenvolva e estimule o gosto pelo acto intelectual de aprender” (CANÁRIO, 2005, p. 87). Tal propósito requer que se comece a "pensar a escola a partir do não escolar", isto é, a partir das práticas educativas e das aprendizagens significativas que se realizam no seu exterior e se configuram como "portadoras de futuro" (CANÁRIO, 2005, p. 88). Como facilmente se depreende, trata-se de uma mudança que implica passar de um paradigma educativo que se centra no ensino e na figura do professor para um paradigma que se desenvolve em torno da aprendizagem e faz dos alunos os principais protagonistas.

Em quinto lugar, torna-se imprescindível revalorizar, em termos públicos, a profissão docente, um processo que tem de desabrochar no interior da própria classe. É por demais evidente a existência de certa imagem negativa sobre as escolas e os professores, um fato de que não estão isentos de culpas nem os professores, nem o próprio poder político. Uma das dificuldades que mais têm condicionado o trabalho dos professores e concorrido para fragilizar o seu papel como gestores curriculares resulta de algumas expectativas [nalguns casos, desconfiança] que criaram em relação às propostas do Ministério da Educação. Não deixando de reconhecer que a profissão docente se encontra, atualmente, num intenso "processo de redefinição e de diversificação das suas funções no seio das escolas", o que determina que os professores sejam "chamados a desempenhar um conjunto alargado de papéis, numa dinâmica de (re)invenção da profissão de professor" (NÓVOA, 1992, p. 36), a verdade é que existe um conjunto de imposições administrativas com que os docentes e as escolas se têm deparado - constituição dos agrupamentos de escolas e dos departamentos curriculares, diferenciação da carreira docente, novo modelo de avaliação do desempenho - e que, em vez de os galvanizarem para a mudança, têm gerado alguma descrença no discurso político, provocado instabilidade e desinteresse e gerado algumas resistências no interior das escolas.

Em sexto lugar, é preciso apostar numa outra formação de professores, uma vez que, em muitos casos, continuam a predominar modelos teóricos baseados numa racionalidade tecnológica e a enaltecer-se a importância das teorias científicas para produzir normas de atuação prá- 
tica. Por outro lado, é necessário que os professores se desfaçam das posturas individualistas que têm caracterizado o seu dia a dia profissional, passem a trabalhar em equipe e reflitam conjuntamente sobre o que fazem, como fazem e por que é que o fazem. Como sustenta Antonio Bolívar (2007, p. 20), a mudança dirime-se "no que os sujeitos sejam capazes de pensar e fazer com ela", o que comprova que a mudança deve ser idealizada pelos próprios professores e não para os professores. Aliás, quando a mudança é promovida de um modo gerencialista é efêmera e ineficaz.

Só que, para os professores conseguirem trabalhar numa lógica de colegialidade e de projeto é preciso romper com certa "liturgia formativa tradicional", que insiste em formar profissionais mais para o terreno da execução do que da decisão. Os desafios que hoje se colocam a nível curricular carecem de professores com capacidades de iniciativa e de decisão, não só em termos de gestão curricular, mas também no domínio da concepção e da realização de projetos, do recurso a metodologias inovadoras e a estilos de ensino que lhes permitam adaptar os processos de ensino-aprendizagem às características, aos interesses, às motivações e aos ritmos de aprendizagem dos alunos com que trabalham.

Por último, a mudança das práticas curriculares docentes. Qualquer reforma que descure esse aspecto estará condenada ao fracasso. O papel que os professores desempenham é crucial para mudar/melhorar as instituições de ensino e, por consequência, o próprio fenômeno educativo. Nesse sentido, torna-se necessário compreender que a sua atividade profissional não pode restringir-se apenas às funções que lhe estão consignadas legalmente, uma vez que o profissionalismo docente resulta em grande parte de tarefas que se inscrevem para além dos conteúdos funcionais prescritos, corporizando o que Organ (1988, p. 4) denomina por "comportamentos de cidadania organizacional", para identificar um conjunto de "comportamentos discricionários, indirecta ou explicitamente reconhecidos pelo sistema de recompensa formal e que, em conjunto, promovem o funcionamento eficaz da organização". Em suma, é necessário que os professores consigam ir mais além do que aquilo que lhes é prescrito, assumindo-se como profissionais autônomos que tomam decisões em prol do conjunto concreto de alunos com que trabalham. 


\section{Conclusão}

Em jeito de balanço final, e tendo em conta algumas das ideias que vimos escalpelizando, importa sinalizar alguns aspectos que, em simultâneo, constituem o ponto de chegada deste texto e um ponto de partida para novas reflexões.

Desde logo, a importância que a educação continua a assumir numa sociedade que evolui e se transmuta rapidamente e nos compele a aprender de forma contínua, ao longo da vida. A afirmação de novos paradigmas políticos, econômicos, sociais e culturais, sobretudo nas últimas décadas do século passado, contribuiu para reconfigurar as exigências e as prioridades educativas e, ao mesmo tempo, para fazer da educação um dos eixos estruturantes dos tempos e ciclos da peregrinação bumana (CARNEIRO, 2003). Os sistemas educativos atuais, mais libertos da pressão da quantidade, progressivamente atenuada pelo acesso alargado das populações aos benefícios da educação, veem-se agora incumbidos de ganhar os desafios da qualidade, da diversidade e da diferenciação, para combater assimetrias sociais e culturais, satisfazer necessidades básicas de escolarização e fazer da educação esteio de equidade, de justiça, de solidariedade e de coesão social.

Tais propósitos exigem uma transformação profunda da escola. Uma transformação que permita que a escola, mais do que um objeto de pedagogia cívica, se assuma como entidade geradora de civismo e de capital social em seu redor (CARNEIRO, 2003). Todavia, a construção de uma entidade com tais características é um processo complexo que depende de inúmeras variáveis estruturais, funcionais e situacionais, cuja ausência inviabilizará qualquer tentativa de mudança. Além disso, por mais garantias que possam ser acauteladas, a transformação da escola só será realidade se resultar da mudança das práticas curriculares dos professores que nela laboram, o que requer a modificação do seu pensamento, o aumento da sua motivação e do seu empenho e, sobretudo, a melhoria das suas competências profissionais.

Finalmente, a necessidade da educação se assumir como um desígnio nacional. Primeiro por não ser justo continuar a assacar à escola certas responsabilidades que incumbem à própria sociedade. Depois porque pensar a educação é pensar a sociedade no seu todo, isto é, no seu patrimônio cultural, nos seus valores, nas suas ambições e nas suas utopias. Só assim a escola poderá converter-se num espaço de participação social e num local de vivência democrática. 
Notas

${ }^{1}$ CANÁRIO (2005), FERRER (2002a; 2002b), ENGUITA (2007), BARROSO (2001), entre outros.

${ }^{2}$ Mariano Enguita (2005, p. 26-27) considera a existência de três tipos de mudanças, mais ou menos coincidentes com três épocas distintas na história da humanidade, que identifica da seguinte forma: mudança suprageracional, mudança intergeracional e mudança intrageracional. 3

A teoria do capital humano desenvolveu-se a partir dos trabalhos de vários economistas, com destaque para os de Theodore Schultz (1961) e Gary Becker (1964). À luz dessa teoria, "o processo de aprendizagem de técnicas, capacidades e conhecimentos através da educação devia ser considerado não como uma mera forma de consumo, mas como um investimento produtivo" (FERNANDES, 1991, p. 49).

${ }^{4}$ A teoria funcional e modernista foi desenvolvida por vários sociólogos, dos quais se destacam os trabalhos de Alex Inkeles e David Smith (1974). Na perspectiva dessa teoria, "a moderna sociedade industrial, quando se compara com a sociedade tradicional, é vista em termos da sua especializada e cada vez mais elaborada divisão do trabalho, a qual requer a participação de cidadãos devidamente qualificados e socializados" (PAPAGIANNIS, 1992, p. 4647). Daí a importância consignada às tecnologias e à inovação como forças propulsoras da capacidade econômica e social dos cidadãos e, por consequência, imprescindíveis para "elevar o grau de desenvolvimento da sociedade" (PAPAGIANNIS, 1992, p. 4647).

${ }^{5} \mathrm{O}$ aumento do preço do petróleo provocou uma enorme subida de preços, vendo-se muitos Estados forçados a abdicar de certas políticas sociais que vinham implementando e a reduzir fortemente os gastos em determinados setores. Curiosamente, vive-se hoje em Portugal (e no mundo) uma situação em tudo idêntica àquela.

${ }^{6}$ Citado por Canário (2005, p. 85).

${ }^{7}$ O conceito de binómio curricular, proposto por Maria do Céu Roldão (1999, p. 33), é idealizado como uma fórmula capaz de contribuir para pensar o currículo de modo a conseguir que a escola garanta "uma qualidade educativa satisfatória" a todos os alunos, respondendo assim aos imperativos democráticos que sobre ela impendem. Nessa ordem de ideias, considera que o currículo deve ser pensado e concretizado por meio de um binômio que abarca, num dos termos, o core curriculum e, no outro, "a concretização que cada escola faz desse core curriculum, concebendo-o como um projecto curricular".

${ }^{8}$ Convém referir que o conceito de core curriculum, definido como o conjunto de "aprendizagens essenciais comuns", socialmente reconhecidas como "competência(s) indispensável(is)" que qualquer aluno deve adquirir na escola (ROLDÃO, 1999, p. 33), não é coincidente com o conceito de currículo nacional, uma vez que este se configura com um empreendimento de maior abrangência que inclui aquele.

9 Andy Hargreaves e Dean Fink (2007, p. 21) designam este movimento como "movimento da reforma educativa e dos padrões de desempenho [standards]", esclarecendo que o conceito de padrão é importante e construtivo, que "exprime a noção de que a aprendizagem tem prioridade sobre o ensino e que deveríamos ser capazes de saber e de demonstrar quando é que essa aprendizagem ocorre efectivamente". 
10

Citado por Bolívar (2006, p. 24).

$\mathrm{O}$ fato de se determinarem metas ou standards a atingir pelos alunos não nos parece negativo, nem mesmo que colida com os propósitos mais amplos de uma educação democrática ou de garantir o direito de todos a uma educação básica de qualidade. O problema é quando esses standards se transformam em fator de selecção das escol(h)as, relegando para segundo plano as escolas (ou os indivíduos) que não conseguem concretizá-los.

${ }^{12}$ Citado por Barroso (2006, p. 38).

\section{Referências bibliográficas}

BARROSO, J. Descentralização e autonomia: devolver o sentido cívico e comunitário à escola pública. Colóquio/Educação e Sociedade, 4, p. 32-58, 1998.

BARROSO, J. O século da escola: do mito da reforma à reforma de um mito. In: AMBRÓSIO, T; TÉRREN, E; HAMELINE, D; BARROSO, J. O século da escola: entre a utopia e a burocracia. Porto: Edições Asa, 2001. p. 63-94.

BECKER, G. S. El capital humano. Madrid: Alianza, 1964.

BOLIVAR, A. Um olhar actual sobre a mudança educativa: onde situar os esforços de melhoria? In: LEITE, C; LOPES, A. (Org.) Escola, Currículo e Formação de Identidades. Porto: Edições Asa, 2007. p. 13-50.

CANÁRIO, R. O que é a Escola? Um “olhar” sociológico. Porto: Porto Editora, 2005.

CARNEIRO, R. Fundamentos da Educação e da Aprendizagem. Vila Nova de Gaia: Fundação Manuel Leão, 2003.

COOMBS, Ph. H. La crisis mundial de la educación. Barcelona: Península, 1971.

DALE, R. Globalização e Educação: demonstrando a existência de uma "Cultura Educacional Mundial Comum” ou localizando uma "Agenda Globalmente Estruturada para a Educação”? Educação, Sociedade \& Culturas, 16, p. 133-169, 2001.

ENGUITA, M. F. Educação e Transformação Social. Mangualde: Edições Pedago, 2007.

FERNANDES, A. S. A problemática social da educação escolar. In: PIRES, E. L; FER-

NANDES, A. S.; FORMOSINHO, J. A Construção Social da Educação Escolar. Porto: Edições Asa, 1991. p. 48-60.

FERRER, A. T. Presentación. In: FERRER, A. T. et al. (Coord.) Historia de la Educación (Edad Contemporánea). Madrid: Universidad Nacional de Educación a Distancia, 2002a. p. 15-17.

FERRER, A. T. Reconstrucción de los sistemas educativos después de la Segunda Guerra Mundial. In: FERRER, A. T. et al. (Coord.) Historia de la Educación (Edad Contemporánea). Madrid: Universidad Nacional de Educación a Distancia, 2002b. p. 259-280.

FORMOSINHO, J. O currículo uniforme pronto-a-vestir de tamanho único. In: O insucesso escolar em questão. Cadernos de análise social da Educação. Braga: Universidade do Minho, p. 41-50, 1987.

HARGEAVES, A.; FINK, D. Liderança Sustentável. Porto: Porto Editora, 2007.

HELD, D. Modelos de Democracia. 2 ed. Madrid: Alianza, 2001.

INKELES, A.; SMITH, D. Becoming Modern: Individual Change in Six Developing Countries. Cambridge: Harvard University Press, 1974. 
KEYNES, J. M. Teoría general de la ocupación, el interés y el dinero. México: Fondo de Cultura Económica, 1974.

LEITE, C. A territorialização das políticas e das práticas educativas. In: LEITE, C. (Org.) Mudanças Curriculares em Portugal. Transição para o Século XXI. Porto: Porto Editora, 2005. p. 15-32.

MEURET, D. La autonomía de los centros escolares y su regulación. Revista de Educación, n. 333, enero-abril, (Madrid, Ministerio de Educación, Cultura y Deporte), p. 11-40, 2004.

MORGADO, J. Processos e práticas de (re)construção da autonomia curricular. Tese (Doutorado) Braga: Universidade do Minho, 2003.

MORGADO, J. Curriculo e Profissionalidade Docente. Porto: Porto Editora, 2005.

MORGADO, J.; FERREIRA, J. Globalização e autonomia: desafios, compromissos e incongruências. In: MOREIRA A.; PACHECO, J. (Orgs.) Globalização e Educação: desafios para políticas e práticas. Porto: Porto Editora, 2006. p. 61-86.

NÓVOA, A. Para um análise das instituições escolares. In NÓVOA, A. (Coord.). As organizações escolares em análise. Lisboa: Dom Quixote/I.I.E., 1992. p. 13-43, p. 36.

ORGAN, D. Organizational Citizenship Behavior: the Good Soldier Syndrome. Lexington MA: Lexington Books, 1988.

PACHECO, J. Politicas curriculares. Referenciais para análise. Porto Alegre: ArtMed, 2003. PACHECO, J. Políticas educativas e curriculares. Para uma análise do contexto português. Conferências plenárias e painéis do IX Congresso da SPCE. Madeira: Universidade da Madeira, 2007.

PAPAGIANNIS, G. J. Políticas de reforma educativa. In: HÚSEN, T.; POSTLETHWAITE, T. N. (Dirs.) Enciclopedia Internacional de la Educación. Barcelona: Vicens-Vives, 1989-1992, V. 8, p. 4646-4653.

POPPER, K. O mito do contexto. Em defesa da ciência e da racionalidade. Lisboa: Edições 70, 1999.

ROLDÃO, M. C. Gestão curricular: fundamentos e práticas. Lisboa: Ministério da Educação, 1999.

SCHULTZ, T. W. Investment in Human Capital. American Economic Review, 51, p. 1-17, 1961.

\author{
Endereço para correspondência: \\ Universidade do Minho \\ Instituto de Educação e Psicologia \\ Departamento de Currículo e Tecnologia Educativa \\ Campus de Gualtar \\ Gualtar \\ 4710-057 \\ Braga - Portugal
}

Data de recebimento: 15/01/2010

Data de aprovação: 16/02/2010 